\title{
Some new fixed point theorems for set-valued contractions in complete metric spaces
}

\author{
Chi-Ming Chen
}

Correspondence: ming@mail.nhcue. edu.tw

Department of Applied

Mathematics, National Hsinchu University of Education, Taiwan

\begin{abstract}
In this article, we obtain some new fixed point theorems for set-valued contractions in complete metric spaces. Our results generalize or improve many recent fixed point theorems in the literature.

MSC: 47H10, 54C60, 54H25, 55M20.
\end{abstract}

Keywords: fixed point theorem, set-valued contraction

\section{Introduction and preliminaries}

Let $(X, d)$ be a metric space, $D$ a subset of $X$ and $f: D \rightarrow X$ be a map. We say $f$ is contractive if there exists $\alpha \in[0,1)$ such that for all $x, y \in D$,

$$
d(f x, f y) \leq \alpha \cdot d(x, y)
$$

The well-known Banach's fixed point theorem asserts that if $D=X, f$ is contractive and $(X, d)$ is complete, then $f$ has a unique fixed point in $X$. It is well known that the Banach contraction principle [1] is a very useful and classical tool in nonlinear analysis. Also, this principle has many generalizations. For instance, a mapping $f: X \rightarrow X$ is called a quasi-contraction if there exists $k<1$ such that

$$
d(f x, f y) \leq k \cdot \max \{d(x, y), d(x, f x), d(y, f y), d(x, f y), d(y, f x)\}
$$

for any $x, y \in X$. In 1974, C'iric' [2] introduced these maps and proved an existence and uniqueness fixed point theorem.

Throughout we denote the family of all nonempty closed and bounded subsets of $X$ by $C B(X)$. The existence of fixed points for various multi-valued contractive mappings had been studied by many authors under different conditions. In 1969, Nadler [3] extended the famous Banach Contraction Principle from single-valued mapping to multi-valued mapping and proved the below fixed point theorem for multi-valued contraction.

Theorem $1[3]$ Let $(X, d)$ be a complete metric space and $T: X \rightarrow C B(X)$. Assume that there exists $c \in[0,1)$ such that

$$
\mathcal{H}(T x, T y) \leq c d(x, y) \quad \text { for all } x, y \in X
$$

where $\mathcal{H}$ denotes the Hausdorff metric on $C B(X)$ induced by $d$, that is, $H(A, B)=\max$ $\left\{\sup _{x \in A} D(x, B), \sup _{y \in B} D(y, A)\right\}$, for all $A, B \in C B(X)$ and $D(x, B)=\inf _{z \in B} d(x, z)$. Then, $T$ has a fixed point in $X$.

(c) 2011 Chen; licensee Springer. This is an Open Access article distributed under the terms of the Creative Commons Attribution License (http://creativecommons.org/licenses/by/2.0), which permits unrestricted use, distribution, and reproduction in any medium, provided the original work is properly cited. 
In 1989, Mizoguchi-Takahashi [4] proved the following fixed point theorem.

Theorem 2 [4] Let $(X, d)$ be a complete metric space and $T: X \rightarrow C B(X)$. Assume that

$$
\mathcal{H}(T x, T y) \leq \xi(d(x, y)) \cdot d(x, y)
$$

for all $x, y \in X$, where $\xi:[0, \infty) \rightarrow[0,1)$ satisfies $\lim \sup _{s \rightarrow t^{+}} \xi(s)<1$ for all $t \in[0$, $\infty)$. Then, $T$ has a fixed point in $X$.

In the recent, Amini-Harandi [5] gave the following fixed point theorem for setvalued quasi-contraction maps in metric spaces.

Theorem 3 [5]Let $(X, d)$ be a complete metric space. Let $T: X \rightarrow C B(X)$ be a k-setvalued quasi-contraction with $k<\frac{1}{2}$, that is,

$$
\mathcal{H}(T x, T y) \leq k \cdot \max \{(x, y), D(x, T x), D(y, T y), D(x, T y)), D(y, T x)\}
$$

for any $x, y \in X$. Then, $T$ has a fixed point in $X$.

\section{Fixed point theorem (I)}

In this section, we assume that the function $\psi: \mathbb{R}^{+5} \rightarrow \mathbb{R}^{+}$satisfies the following conditions:

(C1) $\psi$ is a strictly increasing, continuous function in each coordinate, and

(C2) for all $t \in \mathbb{R}^{+}, \psi(t, t, t, 0,2 t)<t, \psi(t, t, t, 2 t, 0)<t, \psi(0,0, t, t, 0)<t$ and $\psi(t, 0,0$, $t, t)<t$.

Definition 1 Let $(X, d)$ be a metric space. The set-valued map $T: X \rightarrow X$ is said to be a set-valued $\psi$-contraction, if

$$
\mathcal{H}(T x, T y) \leq \psi(d(x, y), D(x, T x), D(y, T y), D(x, T y)), D(y, T x))
$$

for all $x, y \in X$.

We now state the main fixed point theorem for a set-valued $\psi$-contraction in metric spaces, as follows:

Theorem 4 Let $(X, d)$ be a complete metric space. Let $T: X \rightarrow C B(X)$ be a set-valued $\psi$-contraction. Then, $T$ has a fixed point in $X$.

Proof. Note that for each $A, B \in C B(X), a \in A$ and $\gamma>0$ with $\mathcal{H}(A, B)<\gamma$, there exists $b \in B$ such that $d(a, b)<\gamma$. Since $T: X \rightarrow C B(X)$ is a set-valued $\psi$-contraction, we have

$$
\mathcal{H}(T x, T y) \leq \psi(d(x, y), D(x, T x), D(y, T y), D(x, T y)), D(y, T x))
$$

for all $x, y \in X$. Suppose that $x_{0} \in X$ and that $x_{1} \in X$. Then, by induction and by the above observation, we can find a sequence $\left\{x_{n}\right\}$ in $X$ such that $x_{n+1} \in T x_{n}$ and for each $n \in \mathbb{N}$,

$$
\begin{aligned}
d\left(x_{n+1}, x_{n}\right) & \leq \psi\left(d\left(x_{n}, x_{n-1}\right), D\left(x_{n}, T x_{n}\right), D\left(x_{n-1}, T x_{n-1}\right), D\left(x_{n}, T x_{n-1}\right), D\left(x_{n-1}, T x_{n}\right)\right) \\
& \leq \psi\left(d\left(x_{n}, x_{n-1}\right), d\left(x_{n}, x_{n+1}\right), d\left(x_{n-1}, x_{n}\right), d\left(x_{n}, x_{n}\right), d\left(x_{n-1}, x_{n+1}\right)\right) \\
& \leq \psi\left(d\left(x_{n}, x_{n-1}\right), d\left(x_{n}, x_{n+1}\right), d\left(x_{n-1}, x_{n}\right), 0, d\left(x_{n-1}, x_{n}\right)+d\left(x_{n}, x_{n+1}\right)\right)
\end{aligned}
$$

and hence, we can deduce that for each $n \in \mathbb{N}$,

$$
d\left(x_{n+1}, x_{n}\right) \leq d\left(x_{n}, x_{n-1}\right) .
$$

Let we denote $c_{m}=d\left(x_{m+1}, x_{m}\right)$. Then, $c_{m}$ is a non-increasing sequence and bounded below. Thus, it must converges to some $c \geq 0$. If $c>0$, then by the above inequalities, 
we have

$$
c \leq c_{n+1} \leq \psi\left(c_{n}, c_{n}, c_{n}, 0,2 c_{n}\right) .
$$

Passing to the limit, as $n \rightarrow \infty$, we have

$$
c \leq c \leq \psi(c, c, c, 0,2 c)<c,
$$

which is a contradiction. Hence, $c=0$.

We next claim that the following result holds:

for each $\gamma>0$, there is $n_{0}(\gamma) \in \mathbb{N}$ such that for all $m>n>n_{0}(\gamma)$,

$$
d\left(x_{m}, x_{n}\right)<\gamma . \quad(*)
$$

We shall prove $\left(^{*}\right)$ by contradiction. Suppose that $\left(^{*}\right)$ is false. Then, there exists some $\gamma>0$ such that for all $k \in \mathbb{N}$, there exist $m_{k}, n_{k} \in \mathbb{N}$ with $m_{k}>n_{k} \geq k$ satisfying:

(1) $m_{k}$ is even and $n_{k}$ is odd;

(2) $d\left(x_{m_{k}}, x_{n_{k}}\right) \geq \gamma$;

(3) $m_{k}$ is the smallest even number such that the conditions (1), (2) hold.

Since $c_{m} \searrow 0$, by (2), we have $\lim _{k \rightarrow \infty} d\left(x_{m_{k}}, x_{n_{k}}\right)=\gamma$ and

$$
\begin{aligned}
\gamma & \leq d\left(x_{m_{k}}, x_{n_{k}}\right) \leq \mathcal{H}\left(T x_{m_{k}-1}, T x_{n_{k}-1}\right) \\
& \leq \psi\left(d\left(x_{m_{k}-1}, x_{n_{k}-1}\right), d\left(x_{m_{k}-1}, x_{m_{k}}\right), d\left(x_{n_{k}-1}, x_{n_{k}}\right), d\left(x_{m_{k}-1}, x_{n_{k}}\right), d\left(x_{n_{k}-1}, x_{m_{k}}\right)\right) \\
& \left.\leq \psi\left(c_{m_{k}-1}+d\left(x_{m_{k}}, x_{n_{k}}\right)+c_{n_{k}-1}, c_{m_{k}-1}, c_{n_{k}-1}, c_{m_{k}-1}+d\left(x_{m_{k}}, x_{n_{k}}\right), d\left(x_{m_{k}}, x_{n_{k}}\right)+c_{n_{k}-1}\right)\right) .
\end{aligned}
$$

Letting $k \rightarrow \infty$. Then, we get

$$
\gamma \leq \psi(\gamma, 0,0, \gamma, \gamma)<\gamma
$$

a contradiction. It follows from $\left({ }^{*}\right)$ that the sequence $\left\{x_{n}\right\}$ must be a Cauchy sequence.

Similarly, we also conclude that for each $n \in \mathbb{N}$,

$$
\begin{aligned}
d\left(x_{n}, x_{n+1}\right) & \leq \psi\left(d\left(x_{n-1}, x_{n}\right), D\left(x_{n-1}, T x_{n-1}\right), D\left(x_{n}, T x_{n}\right), D\left(x_{n-1}, T x_{n}\right), D\left(x_{n}, T x_{n-1}\right)\right) \\
& \leq \psi\left(d\left(x_{n-1}, x_{n}\right), d\left(x_{n-1}, x_{n}\right), d\left(x_{n}, x_{n+1}\right), d\left(x_{n-1}, x_{n+1}\right), d\left(x_{n}, x_{n}\right)\right) \\
& \leq \psi\left(d\left(x_{n-1}, x_{n}\right), d\left(x_{n}, x_{n+1}\right), d\left(x_{n-1}, x_{n}\right), d\left(x_{n-1}, x_{n}\right)+d\left(x_{n}, x_{n+1}\right), 0\right)
\end{aligned}
$$

and hence, we have that for each $n \in \mathbb{N}$,

$$
d\left(x_{n}, x_{n+1}\right) \leq d\left(x_{n-1}, x_{n}\right)
$$

Let we denote $b_{m}=d\left(x_{m}, x_{m+1}\right)$. Then, $b_{m}$ is a non-increasing sequence and bounded below. Thus, it must converges to some $b \geq 0$. If $b>0$, then by the above inequalities, we have

$$
b \leq b_{n+1} \leq \psi\left(b_{n}, b_{n}, b_{n}, 2 b_{n}, 0\right) .
$$

Passing to the limit, as $n \rightarrow \infty$, we have

$$
b \leq b \leq \psi(b, b, b, 2 b, 0)<b,
$$

which is a contradiction. Hence, $b=0$. By the above argument, we also conclude that $\left\{x_{n}\right\}$ is a Cauchy sequence. 
Since $X$ is complete, there exists $\mu \in X$ such that $\lim _{n \rightarrow \infty} x_{n}=\mu$. Therefore,

$$
\begin{aligned}
D(\mu, T \mu) & =\lim _{n \rightarrow \infty} D\left(x_{n+1}, T \mu\right) \\
& \leq \lim _{n \rightarrow \infty} \mathcal{H}\left(T x_{n}, T \mu\right) \\
& \leq \lim _{n \rightarrow \infty} \psi\left(d\left(x_{n}, \mu\right), D\left(x_{n}, T x_{n}\right), D(\mu, T \mu), D\left(x_{n}, T \mu\right), D\left(\mu, T x_{n}\right)\right) \\
& \leq \lim _{n \rightarrow \infty} \psi\left(d\left(x_{n}, \mu\right), d\left(x_{n}, x_{n+1}\right), D(\mu, T \mu), D\left(x_{n}, T \mu\right), d\left(\mu, x_{n+1}\right)\right) \\
& \leq \psi(0,0, D(\mu, T \mu), D(\mu, T \mu), 0) \\
& <D(\mu, T \mu),
\end{aligned}
$$

and hence, $D(\mu, T \mu)=0$, that is, $\mu \in T \mu$, since $T \mu$ is closed.

\section{Fixed point theorem (II)}

In 1972, Chatterjea [6] introduced the following definition.

Definition 2 Let $(X, d)$ be a metric space. A mapping $f: X \rightarrow X$ is said to be a $\mathcal{C}$-contraction if there exists $\alpha \in\left(0, \frac{1}{2}\right)$ such that for all $x, y \in X$, the following inequality holds:

$$
d(f x, f y) \leq \alpha \cdot(d(x, f y)+d(y, f x)) .
$$

Choudhury [7] introduced a generalization of $\mathcal{C}$-contraction, as follows:

Definition 3 Let $(X, d)$ be a metric space. A mapping $f: X \rightarrow X$ is said to be a weakly $\mathcal{C}$-contraction if for all $x, y \in X$,

$$
d(f x, f y) \leq \frac{1}{2}(d(x, f y)+d(y, f x)-\phi(d(x, f y), d(y, f x))),
$$

where $\varphi: \mathbb{R}^{+2} \rightarrow \mathbb{R}^{+}$is a continuous function such that $\psi(x, y)=0$ if and only if $x=y=0$. In $[6,7]$, the authors proved some fixed point results for the $\mathcal{C}$-contractions. In this section, we present some fixed point results for the weakly $\psi-\mathcal{C}$-contraction in complete metric spaces.

Definition 4 Let $(X, d)$ be a metric space. The set-valued map $T: X \rightarrow X$ is said to be a set-valued weakly $\psi$-C-contraction, if for all $x, y \in X$

$$
\mathcal{H}(T x, T y) \leq \psi([D(x, T y)+D(y, T x)-\phi(D(x, T y), D(y, T x))]),
$$

where

(1) $\psi: \mathbb{R}^{+} \rightarrow \mathbb{R}^{+}$is a strictly increasing, continuous function with $\psi(t) \leq \frac{1}{2}$ tfor all $t>$ 0 and $\psi(0)=0$;

(2) $\varphi: \mathbb{R}^{+2} \rightarrow \mathbb{R}^{+}$is a strictly decreasing, continuous function in each coordinate, such that $\varphi(x, y)=0$ if and only if $x=y=0$ and $\varphi(x, y) \leq x+y$ for all $x, y \in \mathbb{R}^{+}$.

Theorem 5 Let $(X, d)$ be a complete metric space. Let $T: X \rightarrow C B(X)$ be a set-valued weakly $\mathcal{C}$-contraction. Then, $T$ has a fixed point in $X$.

Proof. Note that for each $A, B \in C B(X), a \in A$ and $\gamma>0$ with $\mathcal{H}(A, B)<\gamma$, there exists $b \in B$ such that $d(a, b)<\gamma$. Since $T: X \rightarrow C B(X)$ be a set-valued weakly $\psi-\mathcal{C}$-contraction, we have that

$$
\mathcal{H}(T x, T y) \leq \psi([D(x, T y)+D(y, T x)-\phi(D(x, T y), D(y, T x))])
$$

for all $x, y \in X$. Suppose that $x_{0} \in X$ and that $x_{1} \in X$. Then, by induction and by the above observation, we can find a sequence $\left\{x_{n}\right\}$ in $X$ such that $x_{n+1} \in T x_{n}$ and for each 
$n \in \mathbb{N}$,

$$
\begin{aligned}
d\left(x_{n+1}, x_{n}\right) & \leq \mathcal{H}\left(T x_{n}, T x_{n-1}\right) \\
& \leq \psi\left(\left[D\left(x_{n}, T x_{n-1}\right)+D\left(x_{n-1}, T x_{n}\right)-\phi\left(D\left(x_{n}, T x_{n-1}\right), D\left(x_{n-1}, T x_{n}\right)\right)\right]\right) \\
& \leq \psi\left(\left[d\left(x_{n}, x_{n}\right)+d\left(x_{n-1}, x_{n+1}\right)-\phi\left(d\left(x_{n}, x_{n}\right), d\left(x_{n-1}, x_{n+1}\right)\right)\right]\right) \\
& =\psi\left(\left[0+d\left(x_{n-1}, x_{n+1}\right)-\phi\left(0, d\left(x_{n-1}, x_{n+1}\right)\right)\right]\right) \\
& \leq \psi\left(\left[d\left(x_{n-1}, x_{n}\right)+d\left(x_{n}, x_{n+1}\right)\right]\right) \\
& \leq \frac{1}{2}\left[d\left(x_{n-1}, x_{n}\right)+d\left(x_{n}, x_{n+1}\right)\right]
\end{aligned}
$$

and hence, we deduce that for each $n \in \mathbb{N}$,

$$
d\left(x_{n+1}, x_{n}\right) \leq d\left(x_{n}, x_{n-1}\right) .
$$

Thus, $\left\{d\left(x_{n+1}, x_{n}\right)\right\}$ is non-increasing sequence and bounded below and hence it is convergent. Let $\lim _{n \rightarrow \infty} d\left(x_{n+1}, x_{n}\right)=\xi$. Letting $n \rightarrow \infty$ in (**), we have

$$
\begin{aligned}
\xi=\lim _{n \rightarrow \infty} d\left(x_{n+1}, x_{n}\right) & \leq \lim _{n \rightarrow \infty} \psi\left(\left[d\left(x_{n-1}, x_{n+1}\right)\right]\right) \\
& \leq \lim _{n \rightarrow \infty} \frac{1}{2}\left[d\left(x_{n-1}, x_{n+1}\right)\right] \\
& \leq \lim _{n \rightarrow \infty} \frac{1}{2}\left[d\left(x_{n-1}, x_{n}\right)+d\left(x_{n}, x_{n+1}\right)\right] \\
& \leq \frac{1}{2}[\xi+\xi]=\xi,
\end{aligned}
$$

that is,

$$
\lim _{n \rightarrow \infty} d\left(x_{n-1}, x_{n+1}\right)=2 \xi
$$

By the continuity of $\psi$ and $\varphi$, letting $n \rightarrow \infty$ in (**), we have

$$
\xi \leq \psi(2 \xi-\phi(0,2 \xi)) \leq \xi-\frac{1}{2} \cdot \phi(0,2 \xi) \leq \xi .
$$

Hence, we have $\varphi(0,2 \xi)=0$, that is, $\xi=0$. Thus, $\lim _{n \rightarrow \infty} d\left(x_{n+1}, x_{n}\right)=0$.

We next claim that the following result holds:

for each $\gamma>0$, there is $n_{0}(\gamma) \in \mathbb{N}$ such that for all $m>n>n_{0}(\gamma)$,

$$
d\left(x_{m}, x_{n}\right)<\gamma . \quad(* * *)
$$

We shall prove $\left(^{* * * *}\right)$ by contradiction. Suppose that $\left.{ }^{(* *)}\right)$ is false. Then, there exists some $\gamma>0$ such that for all $k \in \mathbb{N}$, there exist $m_{k}, n_{k} \in \mathbb{N}$ with $m_{k}>n_{k} \geq k$ satisfying:

(1) $m_{k}$ is even and $n_{k}$ is odd;

(2) $d\left(x_{m_{k}}, x_{n_{k}}\right) \geq \gamma$;

(3) $m_{k}$ is the smallest even number such that the conditions (1), (2) hold.

Since $d\left(x_{n+1}, x_{n}\right) \searrow 0$, by (2), we have $\lim _{k \rightarrow \infty} d\left(x_{m_{k}}, x_{n_{k}}\right)=\gamma$ and

$$
\begin{aligned}
\gamma & \leq d\left(x_{m_{k}}, x_{n_{k}}\right) \leq \mathcal{H}\left(T x_{m_{k}-1}, T x_{n_{k}-1}\right) \\
& \leq \psi\left(\left[D\left(x_{m_{k}-1}, T x_{n_{k}-1}\right)+D\left(x_{n_{k}-1}, T x_{m_{k}-1}\right)-\phi\left(D\left(x_{m_{k}-1}, T x_{n_{k}-1}\right), D\left(x_{n_{k}-1}, T x_{m_{k}-1}\right)\right)\right]\right) \\
& \leq \psi\left(\left[d\left(x_{m_{k}-1}, x_{n_{k}}\right)+d\left(x_{n_{k}-1}, x_{m_{k}}\right)-\phi\left(d\left(x_{m_{k}-1}, x_{n_{k}}\right), d\left(x_{n_{k}-1}, T x_{m_{k}}\right)\right)\right]\right) .
\end{aligned}
$$

Since

$$
d\left(x_{m_{k}-1}, x_{n_{k}}\right)+d\left(x_{n_{k}-1}, x_{m_{k}}\right) \leq d\left(x_{m_{k}-1}, x_{m_{k}}\right)+d\left(x_{m_{k}}, x_{n_{k}}\right)+d\left(x_{n_{k}}, x_{m_{k}}\right)+d\left(x_{n_{k}-1}, x_{n_{k}}\right),
$$


letting $k \rightarrow \infty$, then we get

$$
\gamma \leq \psi(2 \gamma-\phi(\gamma, \gamma)) \leq \gamma,
$$

and hence, $\varphi(\gamma, \gamma))=0$. By the definition of $\varphi$, we get $\gamma=0$, a contradiction. This proves that the sequence $\left\{x_{n}\right\}$ must be a Cauchy sequence.

Since $X$ is complete, there exists $z \in X$ such that $\lim _{n \rightarrow \infty} x_{n}=z$. Therefore,

$$
\begin{aligned}
D(z, T z) & =\lim _{n \rightarrow \infty} D\left(x_{n+1}, T z\right) \\
& \leq \lim _{n \rightarrow \infty} \mathcal{H}\left(T x_{n}, T z\right) \\
& \leq \lim _{n \rightarrow \infty} \psi\left(\left[D\left(x_{n}, T z\right)+D\left(z, T x_{n}\right)-\phi\left(D\left(x_{n}, T z\right), D\left(z, T x_{n}\right)\right)\right]\right) \\
& \leq \lim _{n \rightarrow \infty} \psi\left(\left[D\left(x_{n}, T z\right)+d\left(z, x_{n+1}\right)-\phi\left(D\left(x_{n}, T z\right), d\left(z, x_{n+1}\right)\right)\right]\right) \\
& \leq \frac{1}{2} D(z, T z)
\end{aligned}
$$

and hence, $D(z, T z)=0$, that is, $z \in T z$, since $T z$ is closed.

\section{Fixed point theorem (III)}

In this section, we recall the notion of the Meir-Keeler type function (see [8]). A function $\phi: \mathbb{R}^{+} \rightarrow \mathbb{R}^{+}$is said to be a Meir-Keeler type function, if for each $\eta>0$, there exists $\delta>0$ such that for $t \in \mathbb{R}^{+}$with $\eta \leq t<\eta+\delta$, we have $\phi(t)<\eta$. We now introduce the new notions of the weaker Meir-Keeler type function $\phi: \mathbb{R}^{+} \rightarrow \mathbb{R}^{+}$in a metric space and the $\phi$-function using the weaker Meir-Keeler type function, as follow:

Definition 5 Let $(X, d)$ be a metric space. We call $\phi: \mathbb{R}^{+} \rightarrow \mathbb{R}^{+}$a weaker Meir-Keeler type function, if for each $\eta>0$, there exists $\delta>0$ such that for $x, y \in X$ with $\eta \leq d(x, y)$ $<\delta+\eta$, there exists $n_{0} \in \mathbb{N}$ such that $\varphi^{n_{0}}(d(x, y))<\gamma_{\eta}$.

Definition 6 Let $(X, d)$ be a metric space. A weaker Meir-Keeler type function $\phi ; \mathbb{R}^{+}$ $\rightarrow \mathbb{R}^{+}$is called a $\phi$-function, if the following conditions hold:

$\left(\phi_{1}\right) \phi(0)=0,0<\phi(t)<t$ for all $t>0$;

$\left(\phi_{2}\right) \phi$ is a strictly increasing function;

$\left(\phi_{3}\right)$ for each $t \in \mathbb{R}^{+},\left\{\phi^{n}(t)\right\}_{n \in \mathbb{N}}$ is decreasing;

$\left(\phi_{4}\right)$ for each $t_{n} \in \mathbb{R}^{+} \backslash\{0\}$, if $\lim _{n \rightarrow \infty} t_{n}=\gamma>0$, then $\lim _{n \rightarrow \infty} \phi\left(t_{n}\right)<\gamma$;

$\left(\phi_{5}\right)$ for each $t_{n} \in \mathbb{R}^{+}$, if $\lim _{n \rightarrow \infty} t_{n}=0$, then $\lim _{n \rightarrow \infty} \phi\left(t_{n}\right)=0$.

Definition 7 Let $(X, d)$ be a metric space. The set-valued map $T: X \rightarrow X$ is said to be a set-valued weaker Meir-Keeler type $\phi$-contraction, if

$$
\mathcal{H}(T x, T y) \leq \varphi\left(\frac{1}{2}[D(x, T y)+D(y, T x)]\right)
$$

for all $x, y \in X$.

We now state the main fixed point theorem for a set-valued weaker Meir-Keeler type $\psi$-contraction in metric spaces, as follows:

Theorem 6 Let $(X, d)$ be a complete metric space. Let $T: C B(X)$ be a set-valued weaker Meir-Keeler type $\psi$-contraction. Then, $T$ has a fixed point in $X$.

Proof. Note that for each $A, B \in C B(X), a \in A$ and $\gamma>0$ with $\mathcal{H}(A, B)<\gamma$, there exists $b \in B$ such that $d(a, b)<\gamma$. Since $T: X \rightarrow C B(X)$ be a set-valued $\psi$-contraction, we have that

$$
\mathcal{H}(T x, T y) \leq \varphi\left(\frac{1}{2}[D(x, T y)+D(y, T x)]\right)
$$


for all $x, y \in X$. Suppose that $x_{0} \in X$ and that $x_{1} \in X$. Then, by induction and by the above observation, we can find a sequence $\left\{x_{n}\right\}$ in $X$ such that $x_{n+1} \in T x_{n}$ and for each $n \in \mathbb{N}$,

$$
\begin{aligned}
d\left(x_{n+1}, x_{n}\right) & \leq \varphi\left(\frac{1}{2}\left[D\left(x_{n}, T x_{n-1}\right)+D\left(x_{n-1}, T x_{n}\right)\right]\right) \\
& \leq \varphi\left(\frac{1}{2}\left[d\left(x_{n}, x_{n}\right)+d\left(x_{n-1}, x_{n+1}\right)\right]\right) \\
& \leq \varphi\left(\frac{1}{2}\left[d\left(x_{n-1}, x_{n}\right)+d\left(x_{n}, x_{n+1}\right)\right]\right)
\end{aligned}
$$

and by the conditions $\left(\phi_{1}\right)$ and $\left(\phi_{2}\right)$, we can deduce that for each $n \in \mathbb{N}$,

$$
d\left(x_{n+1}, x_{n}\right) \leq \varphi\left(d\left(x_{n}, x_{n-1}\right)\right)<d\left(x_{n}, x_{n-1}\right)
$$

and

$$
d\left(x_{n+1}, x_{n}\right) \leq \varphi\left(d\left(x_{n}, x_{n-1}\right)\right) \leq \cdots \leq \varphi^{n}\left(d\left(x_{1}, x_{0}\right)\right) .
$$

By the condition $\left(\phi_{3}\right),\left\{\phi^{n}\left(d\left(x_{0}, x_{1}\right)\right)\right\}_{n \in \mathbb{N}}$ is decreasing, it must converges to some $\eta \geq$ 0 . We claim that $\eta=0$. On the contrary, assume that $\eta>0$. Then, by the definition of the weaker Meir-Keeler type function, there exists $\delta>0$ such that for $x_{0}, x_{1} \in X$ with $\eta \leq d\left(x_{0}, x_{1}\right)<\delta+\eta$, there exists $n_{0} \in \mathbb{N}$ such that $\varphi^{n_{0}}\left(d\left(x_{0}, x_{1}\right)\right)<\eta$. Since $\lim _{n \rightarrow \infty} \phi^{n}$ $\left(d\left(x_{0}, x_{1}\right)\right)=\eta$, there exists $m_{0} \in \mathbb{N}$ such that $\eta \leq \phi^{m}\left(d\left(x_{0}, x_{1}\right)\right)<\delta+\eta$, for all $m \geq m_{0}$. Thus, we conclude that $\varphi^{m_{0}+n_{0}}\left(d\left(x_{0}, x_{1}\right)\right)<\eta$. Hence, we get a contradiction. Hence, $\lim _{n \rightarrow \infty} \phi^{n}\left(d\left(x_{0}, x_{1}\right)\right)=0$, and hence, $\lim _{n \rightarrow \infty} d\left(x_{n}, x_{n+1}\right)=0$.

Next, we let $c_{m}=d\left(x_{m}, x_{m+1}\right)$, and we claim that the following result holds: for each $\varepsilon>0$, there is $n_{0}(\varepsilon) \in \mathbb{N}$ such that for all $m, n \geq n_{0}(\varepsilon)$,

$$
d\left(x_{m}, x_{m+1}\right)<\varepsilon . \quad(* * * *)
$$

We shall prove $\left({ }^{* * * * *)}\right.$ by contradiction. Suppose that $(* * * *)$ is false. Then, there exists some $\varepsilon>0$ such that for all $p \in N$, there are $m_{p}, n_{p} \in \mathbb{N}$ with $m_{p}>n_{p} \geq p$ satisfying:

(i) $m_{p}$ is even and $n_{p}$ is odd,

(ii) $d\left(x_{m_{p}}, x_{n_{p}}\right) \geq \varepsilon$, and

(iii) $m_{p}$ is the smallest even number such that the conditions (i), (ii) hold.

Since $c_{m} \searrow 0$, by $(i i)$, we have $\lim _{p \rightarrow \infty} d\left(x_{m_{p}}, x_{n_{p}}\right)=\varepsilon$, and

$$
\begin{aligned}
\varepsilon & \leq d\left(x_{m_{p}}, x_{n_{p}}\right) \\
& \leq \mathcal{H}\left(T x_{m_{p}-1}, T x_{n_{p}-1}\right) \\
& \leq \varphi\left(\frac{1}{2}\left[D\left(x_{m_{p}-1}, T x_{n_{p}-1}\right)+D\left(x_{n_{p}-1}, T x_{m_{p}-1}\right)\right]\right) \\
& \leq \varphi\left(\frac{1}{2}\left[d\left(x_{m_{p}-1}, x_{n_{p}}\right)+d\left(x_{n_{p}-1}, x_{m_{p}}\right)\right]\right) \\
& \leq \varphi\left(\frac{1}{2}\left[d\left(x_{m_{p}-1}, x_{m_{p}}\right)+2 d\left(x_{n_{p}}, x_{m_{p}}\right)+d\left(x_{n_{p}-1}, x_{n_{p}}\right)\right]\right) .
\end{aligned}
$$


Letting $p \rightarrow \infty$. By the condition $\left(\phi_{4}\right)$, we have

$$
\varepsilon \leq \lim _{p \rightarrow \infty} \varphi\left(\frac{1}{2}\left[d\left(x_{m_{p}-1}, x_{m_{p}}\right)+2 d\left(x_{n_{p}}, x_{m_{p}}\right)+d\left(x_{n_{p}-1}, x_{n_{p}}\right)\right]\right)<\varepsilon,
$$

a contradiction. Hence, $\left\{x_{n}\right\}$ is a Cauchy sequence. Since $(X, d)$ is a complete metric space, there exists $\mu \in X$ such that $\lim n \rightarrow \infty x_{n+1}=\mu$. Therefore,

$$
\begin{aligned}
D(\mu, T \mu) & =\lim _{n \rightarrow \infty} D\left(x_{n+1}, T \mu\right) \\
& \leq \lim _{n \rightarrow \infty} \mathcal{H}\left(T x_{n}, T \mu\right) \\
& \leq \lim _{n \rightarrow \infty} \varphi\left(\frac{1}{2}\left[D\left(x_{n}, T \mu\right)\right)+D\left(\mu, T x_{n}\right)\right) \\
& \leq \lim _{n \rightarrow \infty} \varphi\left(\frac{1}{2}\left[D\left(x_{n}, T \mu\right)\right)+d\left(\mu, x_{n+1}\right)\right) \\
& \leq \frac{1}{2} D(\mu, T \mu),
\end{aligned}
$$

and hence, $D(\mu, T \mu)=0$, that is, $\mu \in T \mu$, since $T \mu$ is closed.

\section{Acknowledgements}

This research was supported by the National Science Council of the Republic of China.

\section{Competing interests}

The author declares he has no competing interests

\section{Received: 27 July 2011 Accepted: 31 October 2011 Published: 31 October 2011}

\section{References}

1. Banach, S: Sur les operations dans les ensembles abstraits et leur application aux equations integerales. Fund Math. 3, 133-181 (1922)

2. C'iric', LB: A generalization of Banach's contraction principle. Proc Am Math Soc. 45(2), 45-181 (1974)

3. Nadler, SB Jr: Multi-valued contraction mappings. Pacific J Math. 30, 475-488 (1969)

4. Mizoguchi, N, Takahashi, W: Fixed point theorems for multi-valued mappings on complete metric spaces. J Math Anal Appl. 141, 177-188 (1989). doi:10.1016/0022-247X(89)90214-X

5. Amini-Harandi, A: Fixed point theory for set-valued quasi-contraction maps in metric spaces. Appl Math Lett. 24(2), 24-1794 (2011)

6. Chatterjea, SK: Fixed point theorems. C.R Acad Bulgare Sci. 25, 727-730 (1972)

7. Choudhury, BS: Unique fixed point theorem for weakly $\mathcal{C}$-contractive mappings. Kathmandu Uni J Sci Eng Technol. 5(2), 5-13 (2009)

8. Meir, A, Keeler, E: A theorem on contraction mappings. J Math Anal Appl. 28, 326-329 (1969). doi:10.1016/0022-247X (69)90031-6

doi:10.1186/1687-1812-2011-72

Cite this article as: Chen: Some new fixed point theorems for set-valued contractions in complete metric spaces. Fixed Point Theory and Applications 2011 2011:72.

\section{Submit your manuscript to a SpringerOpen ${ }^{\circ}$} journal and benefit from:

- Convenient online submission

- Rigorous peer review

- Immediate publication on acceptance

- Open access: articles freely available online

- High visibility within the field

- Retaining the copyright to your article

Submit your next manuscript at $\boldsymbol{s p r i n g e r o p e n . c o m ~}$ 